International Journal of Engineering \& Technology, 7 (2.17) (2018) $17-26$
International Journal of Engineering \& Technology
SPC
Website: www.sciencepubco.com/index.php/IJET
Research Paper

\title{
Optimize Transmission of Image over Integrated Mobile WiMAX and WiLAN Network
}

\author{
Anant R. More ${ }^{1 *}$, Wankhede Vishal A. ${ }^{2}$, M.S.G. Prasad ${ }^{3}$ \\ ${ }^{I}$ Ph.D. Scholar, K.L. University, A.P. India and Asst. Prof., RMD Sinhgad School of Engineering, Pune, India \\ ${ }^{2}$ Professor and Head of Department, E \& TC, SNJBs K.B. Jain CoE, Chandwad, Nashik, India and Research Supervisor, \\ KL University, A.P. India \\ ${ }^{3}$ Professor, and Head of Department, ECE, KKR Institute of Technology \& Sciences, Guntur, India and Research Supervisor, \\ KL University, A.P. India \\ *Corresponding author E-mail:anant_anu@yahoo.com
}

\begin{abstract}
The problem of multiuser downlink resource allocation in Mobile WiMAX system was studied. Three different network scenarios considered for the transmission of image data. Resource allocation is done using Active Set Optimization and Genetic Algorithm, for all the three network scenarios. Simulation results show that information fed back and association among subcarriers play vital role to improve system performance. As compared to reduced complexity, resource allocation using Active Set Optimization and Genetic Algorithm seems especially attractive as the number of users increases for Image Data. It is observed through simulation that the System using Genetic Algorithm performs better than Active Set. Linear Resource Allocation in terms of significantly decreasing the computational complexity and achieve higher capacities, while being applicable to a more general class of systems. As Genetic Algorithm follows constraints of Stochastic processes it didn't give results highest in all Experiment Conducted. It is also observed that for Integer-Binary Objective function Performance of Genetic Algorithm is not that much satisfied because of its stochastic processing. Also processing time required to reach final optimize variables values is too much.
\end{abstract}

Keywords: Integrated Mobile WiMAX, resource allocation, Genetic Algorithm, Active-Set optimization.

\section{Introduction}

The problem of multiuser downlink resource allocation in Mobile WiMAX system was studied in last semester. Simulation results showed that information fed back and association among subcarriers play vital role to improve system performance. As compared to reduced complexity resource allocation Active Set Optimization and Genetic Algorithm seems especially attractive as the number of users increases. It is observed through simulation that the System using Genetic Algorithm performs better than Active Set, Linear Resource Allocation and Root Finding in terms of significantly decreasing the computational complexity and achieve higher capacities, while being applicable to a more general class of systems. As Genetic Algorithm follows constraints of Stochastic processes it didn't give results highest in all Experiment Conducted. It is also observed that for IntegerBinary Objective function Performance of Genetic Algorithm is not that much satisfied because of its stochastic processing. Also processing time required to reach final optimize variables values is too much.

As in WiMAX latency period is too important because Base Station have to allot the resources in short span of time to its active users, GA fails to reach Optimize variables value within that period and took too much time. So we came to the conclusion that for such type of Networks Active-Set
Optimization is best suited instead of Genetic Algorithm though the fitness functions value is greater than the results obtained by Active-Set Optimization Technique. Some related signal processing techniques are presented in [9]-[13].

\section{Bitmap packet formations}

Step 1: Input Image with 256 X 256 size used for Transmission using 100 Subcarriers with 64 QAM symbol size is 8 Bits hence $(256 * 256=65536)$ symbols required to transmit our Image.

Table 1: Properties of image

\begin{tabular}{|c|c|c|}
\hline \multicolumn{3}{|c|}{ Table 1: Properties of image } \\
\hline Sr. No. & Attribute & Value \\
\hline 1 & File Name & Antenna256.bmp \\
\hline 2 & Mode & Grayscale \\
\hline 3 & Resolution / size (Pixel) & 256 X 256 \\
\hline 4 & Depth & 8 Bit \\
\hline 6 & Compression & RLE \\
\hline
\end{tabular}




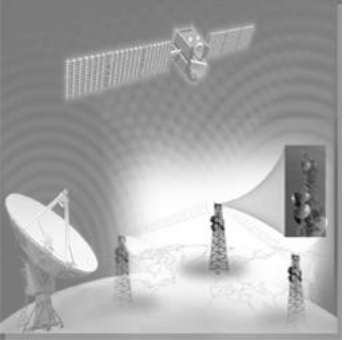

Fig. 1: Image for experiment resolution

Total Number of Symbols for Total 100 Subcarriers $=\frac{65536}{100}=655.36$

Total Number of Frames required to transmit 656 Symbol Data $=\frac{655.36}{48}=13.65$

Hence $13.65 \approx 14$ Frames required to Transmit above mentioned Image. If channel is good then time required to Transmit above Image for our Experiment is:

$64 \mathrm{~KB}=256 * 256 * 8 \mathrm{bits}=524288 \mathrm{Bits}=14 * 5 \mathrm{~ms}=70 \mathrm{~ms}$

524288 Bits transmitted in $70 \mathrm{~ms}$ hence within $1 \mathrm{Sec}$ we can transmit 7489828.5 bits.

Bits per with Bandwidth Requirement is $=100$ (Subcarriers) * $10.94 \mathrm{KHz}$ (subcarriers Spacing) $=1094 \mathrm{KHz}=1.094 \mathrm{MHz}$. Means,

Table 2: Data rate for three modulation schemes

\begin{tabular}{|c|c|c|c|c|}
\hline $\begin{array}{c}\text { Time } \\
\text { Required to } \\
\text { transmit }\end{array}$ & $\begin{array}{c}\text { No. of } \\
\text { Requir } \\
\text { ed }\end{array}$ & $\begin{array}{c}\text { Band } \\
\text { width }\end{array}$ & $\begin{array}{c}\text { Transmitted } \\
\text { Bits }\end{array}$ & $\begin{array}{c}\text { Transmitted } \\
\text { Bits (KB) }\end{array}$ \\
\hline 1 Sec & 14 & $\begin{array}{c}1.094 \\
\mathrm{MHz}\end{array}$ & 7489828.5 & $\begin{array}{c}914.2857 \mathrm{~KB} \\
\text { => 9.14MB }\end{array}$ \\
\hline $\begin{array}{c}\text { Capacity } \\
\text { for(64QAM) }\end{array}$ & \multicolumn{5}{|c|}{$6.84 \mathrm{Bits} / \mathrm{Sec} / \mathrm{Hz}$} \\
\hline & & & & $232.7 \mathrm{~KB}$ \\
\hline QPSK & 55 & $\begin{array}{c}1.094 \\
\mathrm{MHz}\end{array}$ & 1906501.8 & \\
\hline Capacity & & $1.74 \mathrm{Bits} / \mathrm{Sec} / \mathrm{Hz}$ & \\
\hline & & $\begin{array}{c}1.094 \\
\mathrm{MHz}\end{array}$ & 3744914.2 & $457.14 \mathrm{~KB}$ \\
\hline 16QAM & 28 & \multicolumn{5}{|c|}{$3.423 \mathrm{Bits} / \mathrm{Sec} / \mathrm{Hz}$} \\
\hline Capacity & \multicolumn{5}{|c|}{} \\
\hline
\end{tabular}

Step 2: Sample Image Matrix

For simplicity we consider 8 x 8 Image, after reading image file we get Matrix in MATLAB with ASCII values in between 0 to 255. E.g. 144 Represents value of first pixels value of Inputted Image.

\begin{tabular}{||c||c||c||c||c||c||c||c||}
\hline 144 & 154 & 160 & 164 & 159 & 159 & 153 & 150 \\
\hline \hline 182 & 189 & 193 & 196 & 194 & 193 & 183 & 181 \\
\hline 216 & 222 & 226 & 231 & 113 & 222 & 213 & 200 \\
\hline \hline 139 & 111 & 125 & 122 & 109 & 83 & 69 & 48 \\
\hline \hline 16 & 57 & 71 & 116 & 119 & 111 & 15 & 54 \\
\hline \hline 38 & 71 & 37 & 90 & 96 & 86 & 92 & 51 \\
\hline \hline 40 & 36 & 11 & 49 & 41 & 44 & 4 & 60 \\
\hline \hline 26 & 3 & 28 & 27 & 27 & 57 & 2 & 10 \\
\hline \hline
\end{tabular}

Step 3: Conversion of Base for QPSK:

For QPSK we have to change its base from 8 bit to 2 bits per symbol after changing Base of Inputted Image we can calculate following Matrix for 1st row only:

\begin{tabular}{||c||c||c||c||c||c||c||c||}
\hline \hline 144 & 154 & $\mathbf{1 6 0}$ & $\mathbf{1 6 4}$ & $\mathbf{1 5 9}$ & $\mathbf{1 5 9}$ & $\mathbf{1 5 3}$ & $\mathbf{1 5 0}$ \\
\hline \hline $\mathbf{0}$ & $\mathbf{2}$ & 0 & 0 & 3 & 3 & 1 & 2 \\
\hline \hline $\mathbf{0}$ & $\mathbf{2}$ & 0 & 1 & 3 & 3 & 2 & 1 \\
\hline $\mathbf{1}$ & $\mathbf{1}$ & 2 & 2 & 1 & 1 & 1 & 1 \\
\hline \hline $\mathbf{2}$ & $\mathbf{2}$ & 2 & 2 & 2 & 2 & 2 & 2 \\
\hline
\end{tabular}

Step 4: Data Mapping (Data on 100 Subcarriers)

\begin{tabular}{||c||c||c||c||c|c||c|c|c||c||}
\hline $\begin{array}{c}\text { Sub } \\
\text { Carrier } \\
\text { number }\end{array}$ & $\mathbf{1}$ & $\mathbf{2}$ & $\mathbf{3}$ & $\mathbf{4}$ & $\mathbf{5}$ & $\mathbf{6}$ & $\mathbf{7}$ & $\mathbf{8}$ & $\mathbf{9}$ \\
\hline \hline & 0 & 0 & 1 & 2 & 2 & 2 & 1 & 2 & 0 \\
\hline \hline & 3 & 3 & 2 & 1 & 1 & 3 & 3 & 1 & 2 \\
\hline \hline & 3 & 2 & 0 & 0 & 1 & 0 & 3 & 0 & 1 \\
\hline
\end{tabular}

\begin{tabular}{||c||c||c|c|c|c||c|c|c||c||}
\hline $\begin{array}{c}\text { Sub } \\
\text { Carrier } \\
\text { number } \rightarrow\end{array}$ & $\mathbf{1 0}$ & $\mathbf{1 1}$ & $\mathbf{1 2}$ & $\mathbf{1 3}$ & $\mathbf{1 4}$ & $\mathbf{1 5}$ & $\mathbf{1 6}$ & $\mathbf{1 7}$ & $\mathbf{1 8}$ \\
\hline \hline & 0 & 2 & 2 & 0 & 1 & 2 & 2 & 3 & 3 \\
\hline \hline & 2 & 3 & 1 & 1 & 3 & 2 & 1 & 3 & 0 \\
\hline \hline & 2 & 2 & 0 & 0 & 3 & 2 & 0 & 0 & 1 \\
\hline
\end{tabular}

Step 5: DPSK data table

\begin{tabular}{|c||c||c||c||c||c||c||c||c||c||c||c||c||}
\hline 2 & 1 & 4 & 2 & 4 & 1 & 1 & 1 & 1 & 1 & 4 & 4 & 1 \\
\hline \hline 2 & 1 & 1 & 4 & 2 & 3 & 2 & 3 & 1 & 1 & 2 & 2 & 1 \\
\hline 1 & 4 & 3 & 1 & 3 & 2 & 1 & 4 & 3 & 3 & 1 & 3 & 2 \\
\hline \hline 4 & 2 & 3 & 1 & 4 & 2 & 4 & 4 & 4 & 1 & 3 & 3 & 2 \\
\hline
\end{tabular}

\begin{tabular}{c||c||c||c||c||c||c||c||c||c||c||c||}
\hline \hline 4 & 4 & 2 & 3 & 4 & 2 & 1 & 2 & 1 & 2 & 3 & 2 \\
\hline \hline 1 & 2 & 4 & 2 & 3 & 3 & 3 & 1 & 4 & 3 & 1 & 3 \\
\hline \hline 4 & 4 & 1 & 1 & 3 & 4 & 4 & 2 & 1 & 3 & 2 & 3 \\
\hline 3 & 2 & 1 & 1 & 4 & 4 & 4 & 2 & 4 & 2 & 2 & 1 \\
\hline \hline
\end{tabular}

Step 6: Apply output from Step 5 to IFFT to achieve time domain wave

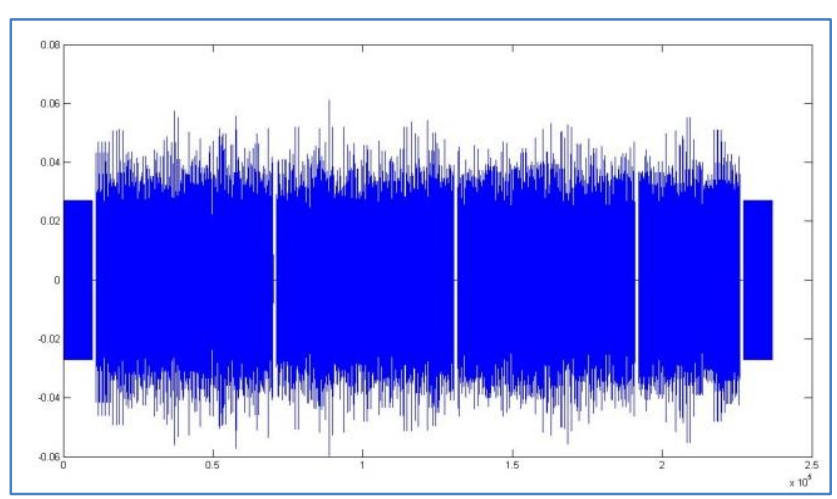

Fig. 2: Time Domain Representation of Frame of $5 \mathrm{~ms}$

\section{Simulation experiment-1}

\subsection{Single User Scenario}

Aims:

1. Vary Image size by keeping SINR constant and Measure Quality of Received Image.

2. Change Modulation Scheme and Measure SNR. 
3. Change Modulation Scheme for Appropriate SNR Range.

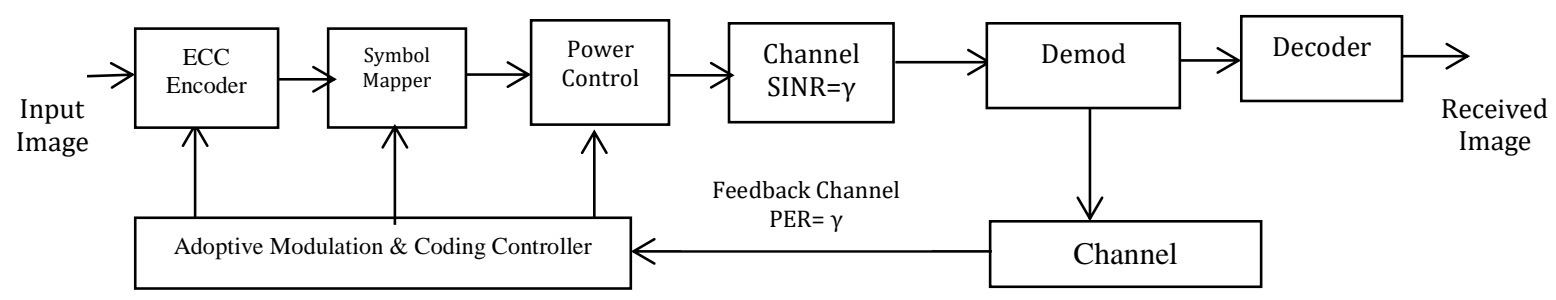

Fig. 3: Single user scenario

Table 3: Parameters considered

\begin{tabular}{|c|c|c|c|}
\hline & \multirow{2}{*}{\multicolumn{2}{|c|}{ Parameter }} & \\
\hline Sr. No. & & & Value \\
\hline 1 & \multicolumn{2}{|l|}{ IFFT size } & 1024 \\
\hline 2 & \multicolumn{2}{|l|}{ Data Subcarrirers } & 720 \\
\hline 3 & \multicolumn{2}{|l|}{ Guard Subcarriers } & 184 \\
\hline 4 & \multicolumn{2}{|l|}{ Pilot Subcarriers } & 120 \\
\hline 5 & \multicolumn{2}{|l|}{ Cyclic Prefix } & $1 / 8$ \\
\hline \multirow{4}{*}{4} & \multirow{4}{*}{ Symbol Size } & BPSK & 1 \\
\hline & & QPSK & 2 \\
\hline & & 16QAM & 4 \\
\hline & & 64QAM & 6 \\
\hline 5 & \multicolumn{2}{|c|}{ Symbol Per Frame for $5 \mathrm{~ms}$ Duration } & 48 \\
\hline 6 & \multicolumn{2}{|c|}{ Channel Bandwidth } & $10 \mathrm{MHz}$ \\
\hline 7 & \multicolumn{2}{|c|}{ Subcarrier frequency spacing } & $10.94 \mathrm{KHz}$ \\
\hline 8 & \multicolumn{2}{|c|}{ Symbol Time } & $91.4 \mu \mathrm{s}$ \\
\hline 9 & \multicolumn{2}{|c|}{ Guard time assuming (12.5\%) } & $11.4 \mu \mathrm{s}$ \\
\hline 10 & \multicolumn{2}{|c|}{ OFDM Symbol Duration } & $102.9 \mu \mathrm{s}$ \\
\hline
\end{tabular}

A block diagram of system is given in Fig. 3. For simplicity, we first consider a single-user system attempting to transmit as quickly as possible through a channel with a variable SINRfor example, due to fading. The goal of the transmitter is to transmit data from its queue as rapidly as possible, subject to the data being demodulated and decoded reliably at the receiver. Feedback is critical for adaptive modulation and

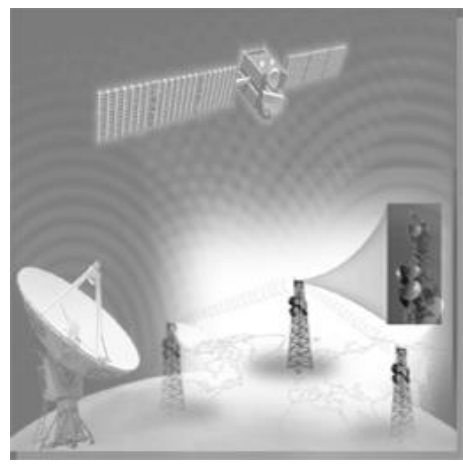

Original Image

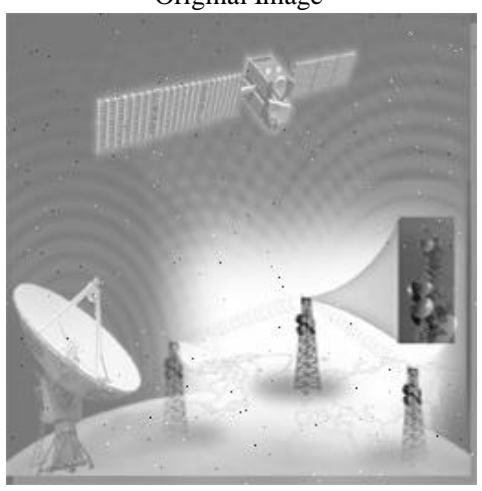

$\mathrm{SNR}=5$
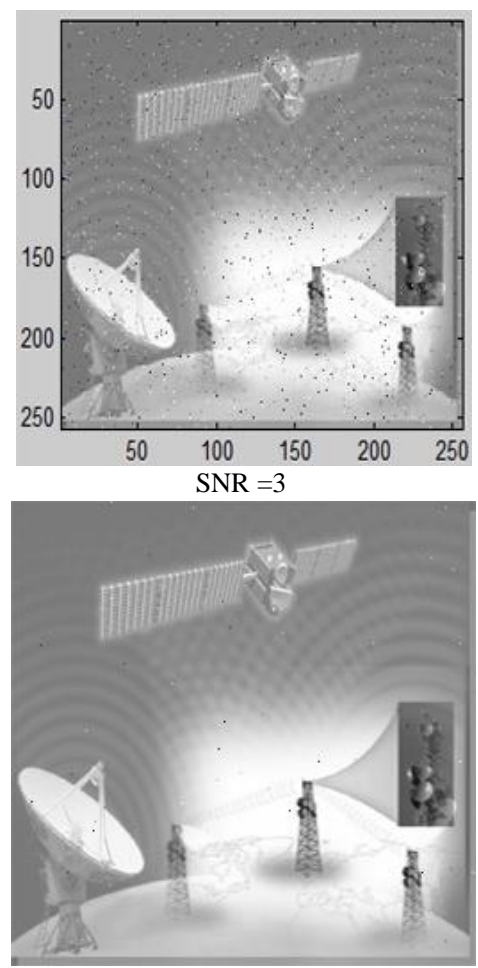

$\mathrm{SNR}=6$

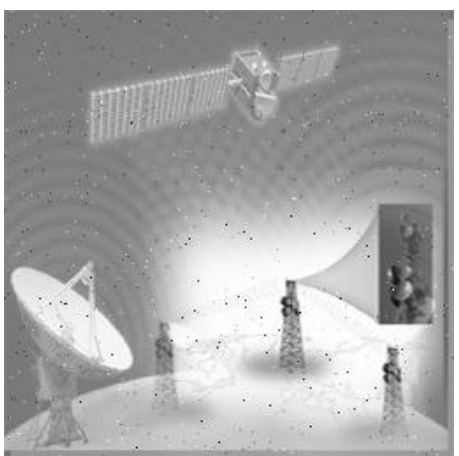

$\mathrm{SNR}=4$

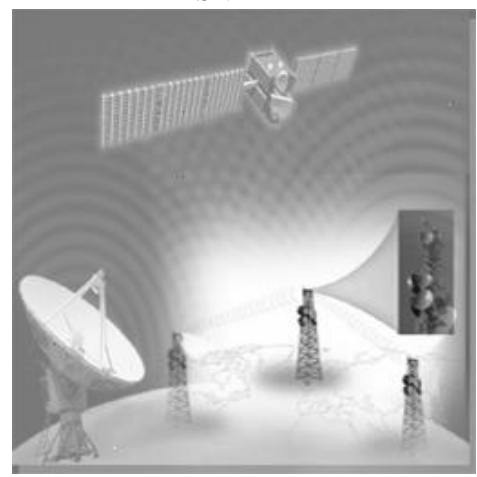

$\mathrm{SNR}=7$

Fig.4: Images received using QPSK on 100 Subcarriers for $\mathrm{SNR}>3$ and $\mathrm{SNR}<7$ 
Similarly we carried out same experiment for 16QAM modulation scheme for different SNR. Following table shows
Image Quality for different SNR for the same parameters set as above.
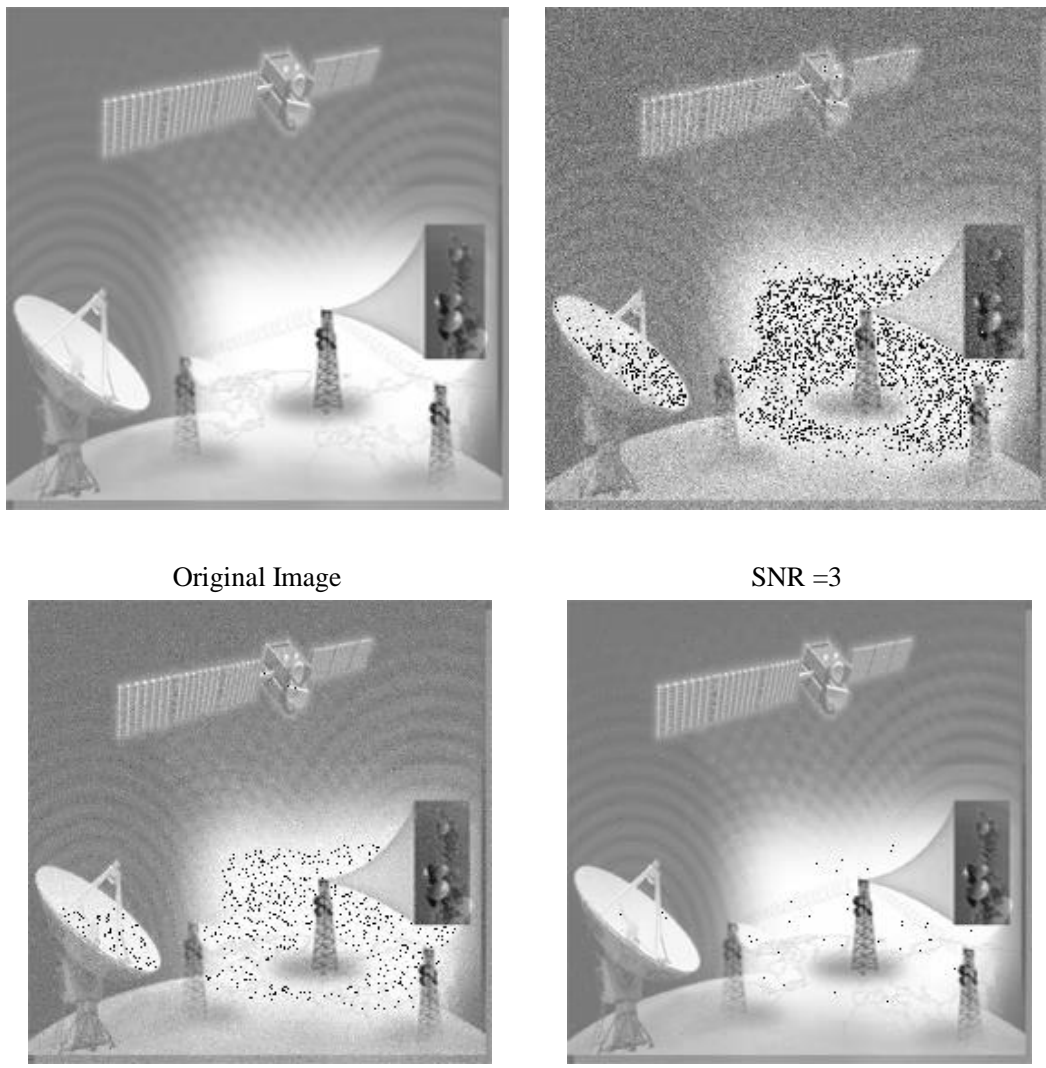

$\mathrm{SNR}=10$

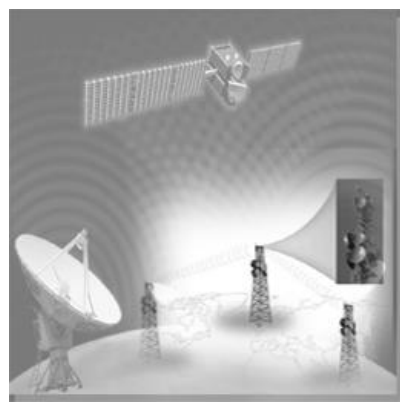

Original Image

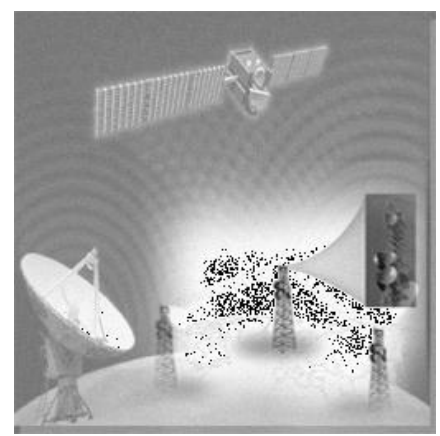

$\mathrm{SNR}=15$
$\mathrm{SNR}=15$

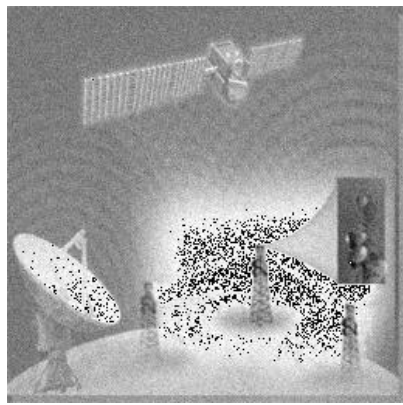

$\mathrm{SNR}=5$

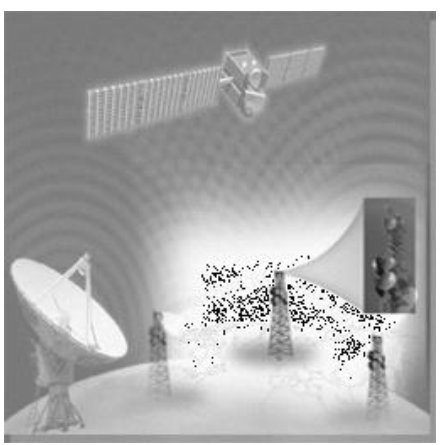

$\mathrm{SNR}=20$

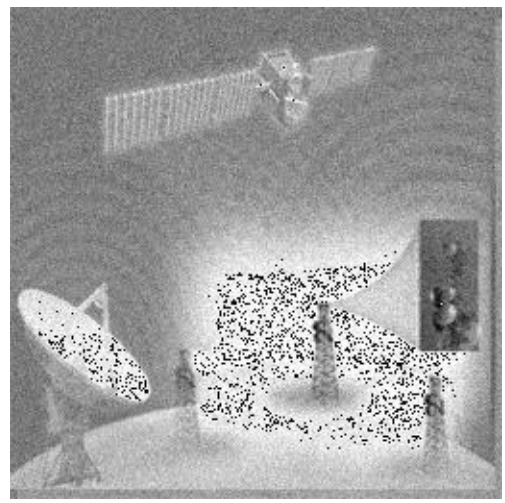

$\mathrm{SNR}=5$

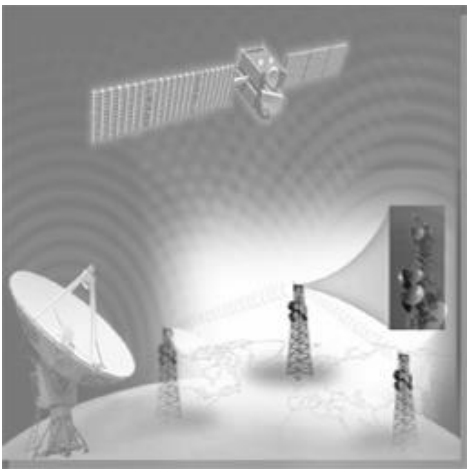

$\mathrm{SNR}=20$

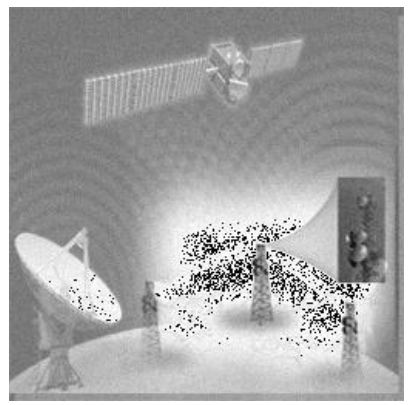

$\mathrm{SNR}=10$

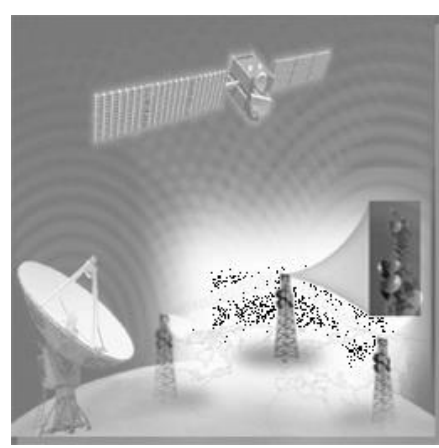

$\mathrm{SNR}=25$

Fig. 5: Images received using 16 and 64 QAM on 100 subcarriers for $\mathrm{SNR}>3$ and $\mathrm{SNR}<25$ 


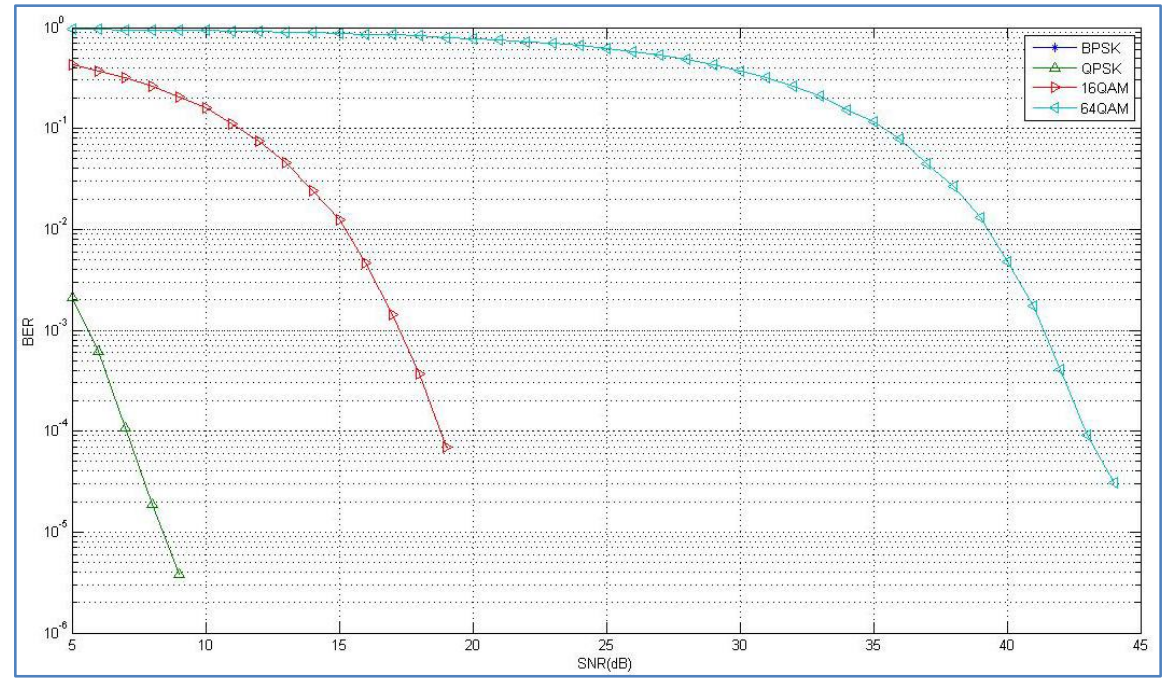

Fig. 6: BER versus SNR for various modulation schemes

\subsection{Policy for AMC controller:}

A key challenge in AMC is to efficiently control three quantities at once: transmit power, transmit rate (constellation), and the coding rate. This corresponds to developing an appropriate policy for the AMC controller. Although reasonable guidelines can be developed from a theoretical study of adaptive modulation, in practice, the system engineer needs to develop and fine-tune the algorithm, based on extensive simulations, since performance depends on many factors. There are a number of ways to take advantage of multiuser diversity and adaptive modulation in OFDMA systems. Algorithms that take advantage of these gains are not specified by the WiMAX standard, and all WiMAX developers are free to develop their own innovative procedures.

\subsection{Ideal distance for various burst profiles}

Table 4: Ideal distance for various modulation schemes

\begin{tabular}{|l|l|}
\hline Modulation Scheme & Recommended Distance $(\mathrm{km})$ \\
\hline 64QAM 3/4 & 0.2 \\
\hline 64QAM 2/3 & 0.4 \\
\hline 16QAM & 0.7 \\
\hline QPSK & $0.7 \quad$ to 1.5 \\
\hline
\end{tabular}

\section{Simulation experiment-2}

\subsection{Two users' scenario}

In this experiment we add one more active user on the network. Both users see channel differently also their QoS requirement is different. Base Station sense QoS for each user and allot Subcarriers and available Transmit Power. Following Table shows details of parameters set for both Users.
Table 5: Two users scenario

\begin{tabular}{|l|l|l|}
\hline Parameter Setting & User 1 & User 2 \\
\hline SNR & 5 & 30 \\
\hline Modulation & QPSK & 64 QAM \\
\hline Word Size & 2 & 6 \\
\hline Subchannels Allotted & $96 / 24 \rightarrow 4$ & $192 / 24 \rightarrow 8$ \\
\hline Power Allocation & $0.1 / 3 \rightarrow 0.033$ & $0.2 / 3 \rightarrow 0.067$ \\
\hline Ifft size & 1024 & 1024 \\
\hline
\end{tabular}

\subsection{Results: Bit error rate versus channel allotted}

In this experiment, we use 24 subcarriers to represent one Subchannel. For User 1 Subchannel allocation is 4 , means information transmitted to User 1 is over 96 Subcarriers, Similarly for User 2, 192 Subcarriers allotted for 8 Subchannels. Total Transmit Power assumed is 0.1; here we scaled down $20 \mathrm{~W}$ of power to 0.1 and accordingly calculations are done. Also it is assumed that User 2 is having more QoS requirement as compared to User 1 hence obviously more power allocation to that User.

Table 6: BER per user versus subchannels allotted

\begin{tabular}{|l|l|l|l|l|l|}
\hline & \multicolumn{2}{|l|}{ USER 1 (BER) } & \multicolumn{3}{|l|}{ USER 2 (BER) } \\
\hline $\begin{array}{l}\text { Sub } \\
\text { channel } \\
\text { s } \\
\text { Allotted }\end{array}$ & $\begin{array}{l}\text { Proportio- } \\
\text { nal } \\
\text { Resource }\end{array}$ & $\begin{array}{l}\text { Active Set } \\
\text { Optimizat } \\
\text { ion }\end{array}$ & $\begin{array}{l}\text { Sub } \\
\text { channels } \\
\text { Allotted }\end{array}$ & $\begin{array}{l}\text { Proportion } \\
\text { al } \\
\text { Resource }\end{array}$ & $\begin{array}{l}\text { Active Set } \\
\text { Optimizat } \\
\text { ion }\end{array}$ \\
\hline 4 & 0.001541 & 0.001782 & 8 & 0.25577 & 0.25418 \\
\hline 5 & 0.004921 & 0.004993 & 9 & 0.28238 & 0.28703 \\
\hline 6 & 0.010654 & 0.010464 & 10 & 0.31012 & 0.30769 \\
\hline 7 & 0.018578 & 0.018608 & 11 & 0.33356 & 0.32907 \\
\hline 8 & 0.027546 & 0.02747 & 12 & 0.34923 & 0.34642 \\
\hline 10 & 0.050415 & 0.050671 & 15 & 0.40385 & 0.40227 \\
\hline 12 & 0.07476 & 0.075645 & 17 & 0.43161 & 0.42813 \\
\hline
\end{tabular}




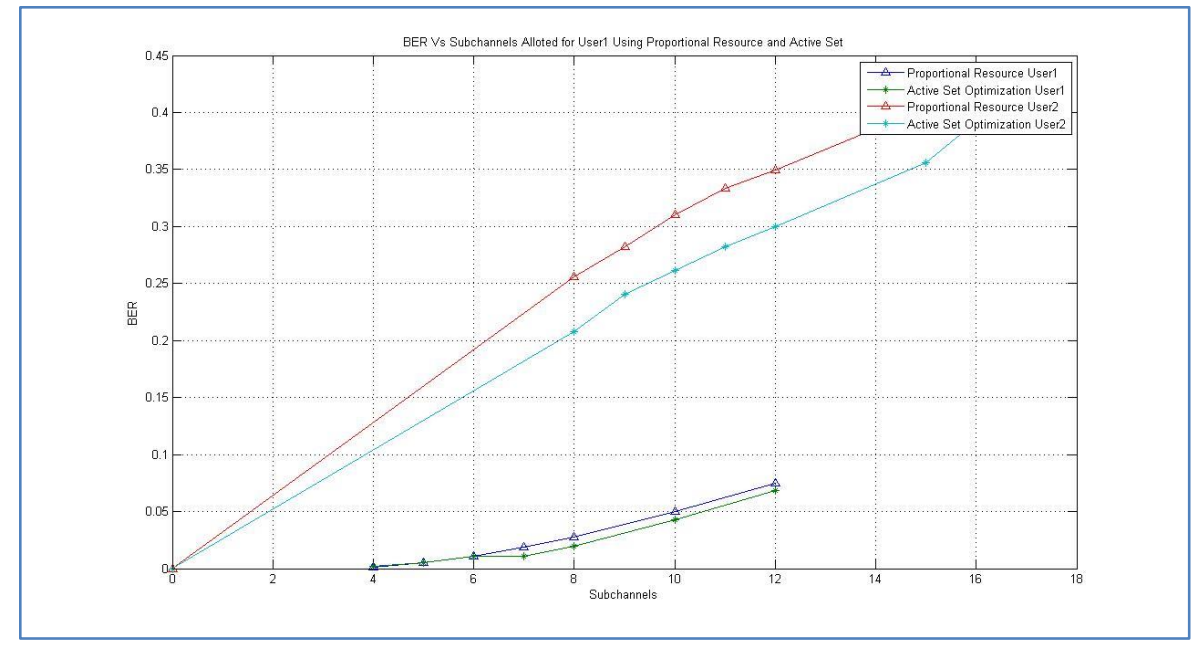

Fig.7: Bit error rate versus subchannels Allotted for both users using PR and AS algorithms.

Table 7: RMS phase error versus subchannels allotted

\begin{tabular}{|c|c|c|c|c|c|}
\hline & \multicolumn{2}{|c|}{ USER 1 (RMS Phase Error) } & \multicolumn{2}{c|}{ USER 2 (RMS Phase Error) } \\
\hline $\begin{array}{c}\text { Subchannels } \\
\text { Allotted }\end{array}$ & $\begin{array}{c}\text { Proportional } \\
\text { Resource }\end{array}$ & $\begin{array}{c}\text { Active Set } \\
\text { Optimization }\end{array}$ & $\begin{array}{c}\text { Subchannels } \\
\text { Allotted }\end{array}$ & $\begin{array}{c}\text { Proportional } \\
\text { Resource }\end{array}$ & $\begin{array}{c}\text { Active Set } \\
\text { Optimization }\end{array}$ \\
\hline 4 & 14.0121 & 14.0531 & 8 & 0.61995 & 0.61841 \\
\hline 5 & 15.7029 & 15.783 & 9 & 0.65205 & 0.65947 \\
\hline 6 & 17.3645 & 17.3386 & 10 & 0.6926 & 0.68753 \\
\hline 7 & 18.84 & 18.838 & 11 & 0.72696 & 0.72147 \\
\hline 8 & 20.1903 & 20.1713 & 12 & 0.75373 & 0.748 \\
\hline 10 & 22.8855 & 22.9309 & 15 & 0.84279 & 0.84362 \\
\hline 12 & 25.3447 & 25.4312 & 17 & 0.89581 & 0.89031 \\
\hline
\end{tabular}

Fig. 7 shows results of Bit Error Rate Versus Number of Subchannels allotted for both users using Proportional Resource and Active Set Optimization. It's seen from fig. 7 as Number of Subchannels increases Bit Error Rate is also Increases. This is because here we keeping channel parameters constant. If channel is poor and Base station in going to increase Subchannels then obviously it will affect Information bits and tends to increase Errors per packet per frame. Hence we suggest that in poor channel conditions Base Station should allot fewer subchannels with burst profile like QPSK so that
Reliability of Information transmission would increase with compromising constraint on Bit Rate or Spectral Efficiency. It's also observed that BER is less using Active Set Optimization as compared to proportional resource. This is only because of Constraints fulfilled by Active Set Optimization to provide more power on Received Effective Subchannel SNR as compared to Proportional Resource.

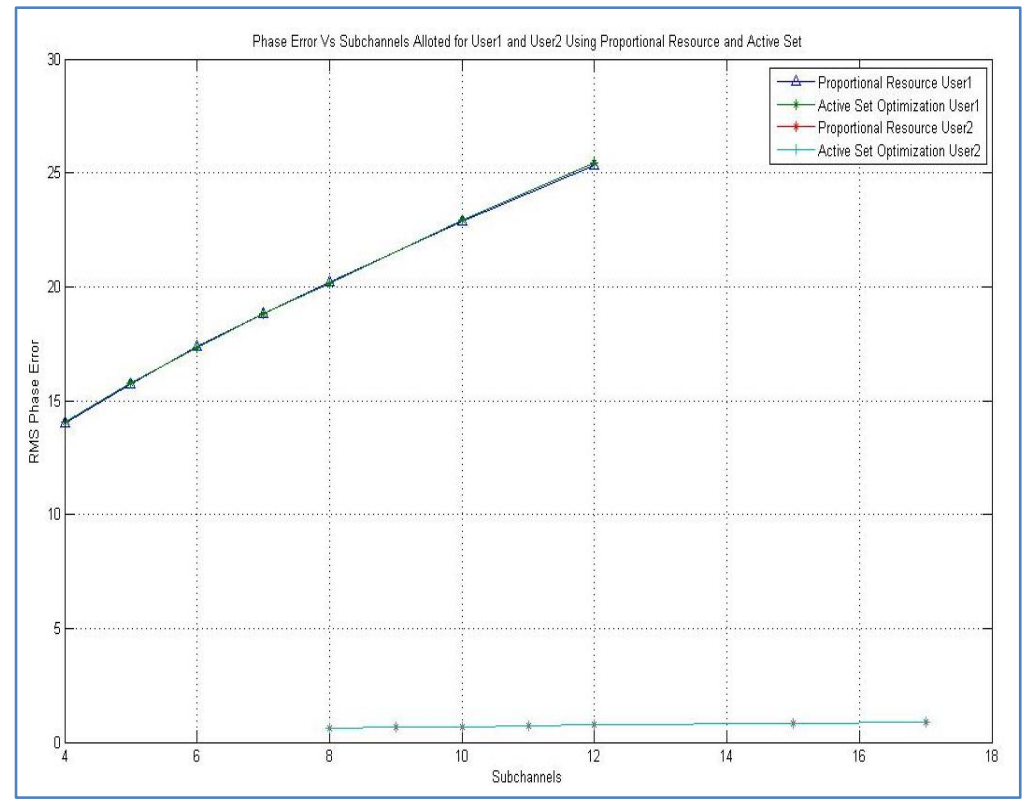

Fig. 8: Subchannels versus RMS phase error 
Fig. 8 Shows graph of Subchannels allotted per user Versus RMS Phase error using Active Set Optimization and Proportional Resource Algorithm. It is observed that there is slight change in RMS Phase error in the Received Signal for Both the algorithms. Also RMS Phase error is very low for 64
QAM Modulation scheme but it is too large for QPSK modulation scheme. Also RMS Phase error recorded using Active Set Optimization is slightly less than Proportional Resource Algorithm.

\subsection{Normalize Euclidian distance}

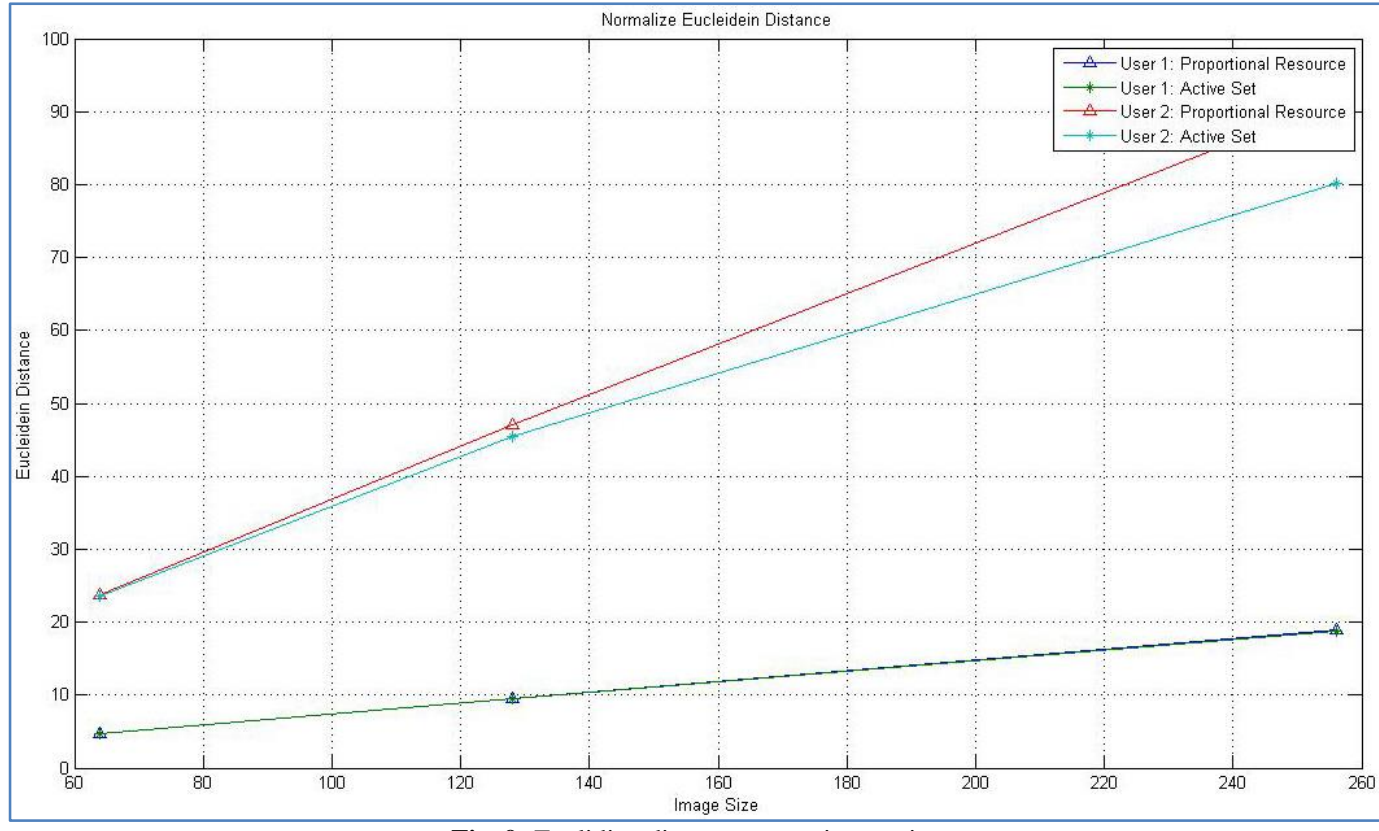

Fig. 9: Euclidian distance versus image size

$$
\text { Euclidian distance }=\frac{\sqrt{\text { OriginalImage }(i, j)^{2}-\text { ReceivedImage }(i, j)^{2}}}{\sum_{i, j=1}^{\text {imax }, j m a x} \sqrt{\text { OriginalImage }(i, j)^{2}}}
$$

Table 8: Euclidian distance for received image for both users

\begin{tabular}{|l|l|l|l|}
\hline \multicolumn{4}{|c|}{ Normalize Euclidian Distance } \\
\hline \multicolumn{2}{|c|}{$\begin{array}{c}\text { User 1 } \\
\text { [SNR=5] } \\
\text { [Subchannels: 4] }\end{array}$} & \multicolumn{2}{|c|}{$\begin{array}{c}\text { User2 } \\
\text { [SNR=30] } \\
\text { [Subchannels: 16] }\end{array}$} \\
\hline $\begin{array}{c}\text { Proportional } \\
\text { Resource }\end{array}$ & $\begin{array}{c}\text { Active Set } \\
\text { Optimization }\end{array}$ & $\begin{array}{c}\text { Proportional } \\
\text { Resource }\end{array}$ & $\begin{array}{c}\text { Active Set } \\
\text { Optimization }\end{array}$ \\
\hline 4.6942 & 4.6942 & 23.7446 & 23.6589 \\
\hline 9.451 & 9.4497 & 47.1168 & 45.401 \\
\hline 18.896 & 18.8034 & 91.4451 & 80.1199 \\
\hline
\end{tabular}

For Poor, Average and Moderate Channel Conditions, Active Set Optimization Performs better than Proportional Resource. For Good channel Conditions Both Provide Similar Results as compared to Euclidian Distance. But Capacity achieved is More Using Active Set Optimization. From Fig.11 we can conclude that as per Quality of Received Image using ActiveSet Optimization is good as compared to Proportional Resource. Hence reliability of Transmitted Bits increases while Using Active Set Optimization rather than Proportional Resource Algorithm.

\section{Simulation experiment-3}

\subsection{System Model}

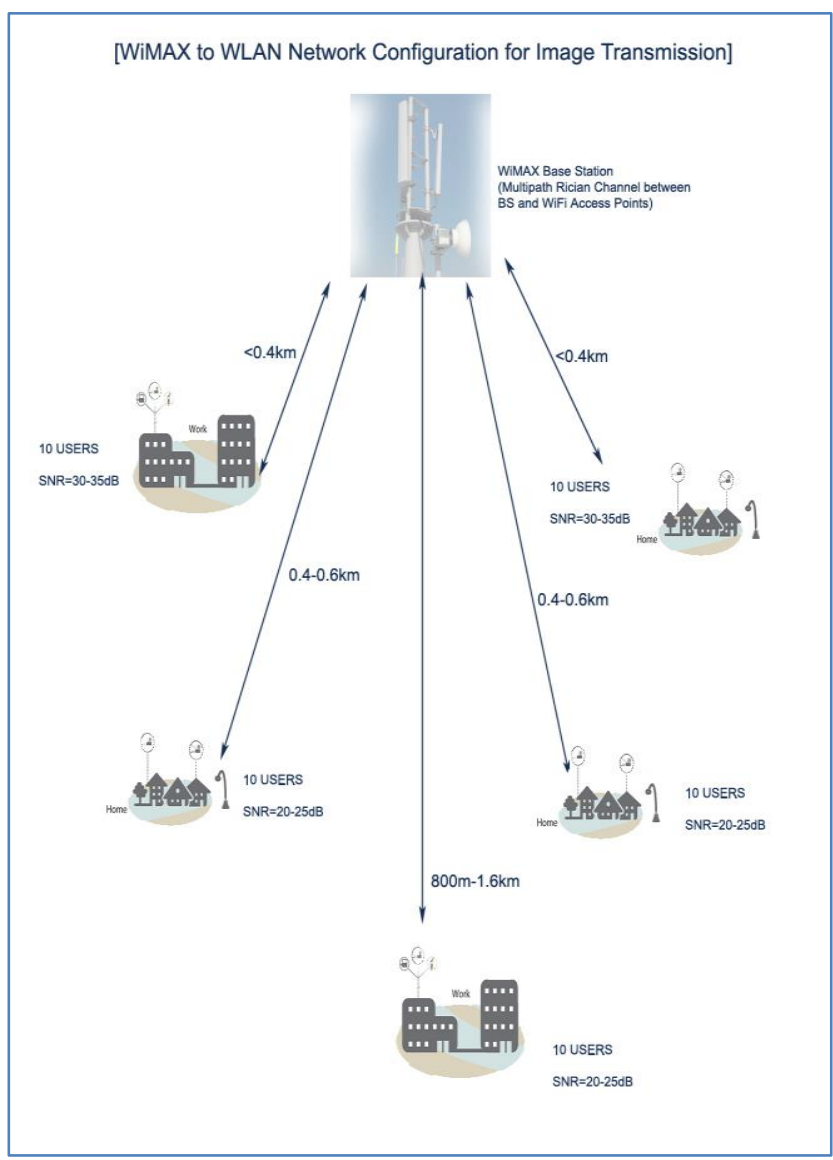

Fig. 10: WiMAX-WLAN network scenario 
Fig. 10 shows system model where one WiMAX Base Station providing Service to five Wireless Local Area Network. It is assumed that each Wireless Local Area Network comprised of 10 Users with different QoS requirement. Also Each WLAN is situated at various distances from Main WiMAX Base Station. With respect to distance and QoS requirement WiMAX Base Station allot different number of Subchannels to those WLAN also Power Allocation is also done by Base Station. Within this network we integrate our Three Algorithms i.e. Proportional Resource, Active-Set Optimization and Genetic Algorithm.

\subsection{Network Parameters}

Following table shows Parameters Considered for Simulation for WiMAX and WLAN networks.

Table 8: WiMAX parameters considered

\begin{tabular}{|c|c|c|c|}
\hline Sr.No. & \multicolumn{2}{|c|}{ Parameter } & Value \\
\hline 1 & \multicolumn{2}{|l|}{ IFFT size } & 1024 \\
\hline 2 & \multicolumn{2}{|l|}{ Data Subcarrirers } & 720 \\
\hline 3 & \multicolumn{2}{|l|}{ Guard Subcarriers } & 184 \\
\hline 4 & \multicolumn{2}{|l|}{ Pilot Subcarriers } & 120 \\
\hline 5 & \multicolumn{2}{|l|}{ Cyclic Prefix } & $1 / 8$ \\
\hline \multirow{4}{*}{4} & \multirow{4}{*}{ Symbol Size } & BPSK & 1 \\
\hline & & QPSK & 2 \\
\hline & & 16QAM & 4 \\
\hline & & 64QAM & 6 \\
\hline 5 & \multicolumn{2}{|c|}{ Symbol Per Frame for $5 \mathrm{~ms}$ Duration } & 48 \\
\hline 6 & \multicolumn{2}{|c|}{ Channel Bandwidth } & $10 \mathrm{MHz}$ \\
\hline 7 & \multicolumn{2}{|c|}{ Subcarrier frequency spacing } & $10.94 \mathrm{KHz}$ \\
\hline 8 & \multicolumn{2}{|c|}{ Symbol Time } & $91.4 \mu \mathrm{s}$ \\
\hline 9 & \multicolumn{2}{|c|}{ Guard time assuming (12.5\%) } & $11.4 \mu \mathrm{s}$ \\
\hline 10 & \multicolumn{2}{|c|}{ OFDM Symbol Duration } & $102.9 \mathrm{Ms}$ \\
\hline
\end{tabular}

Table 9: Wireless LAN parameters considered

\begin{tabular}{|c|l|l|l|}
\hline Sr. No. & \multicolumn{2}{|c|}{ Parameter } & \multicolumn{1}{|c|}{ Value } \\
\hline 1 & IFFT size & 1024 \\
\hline 2 & Number of Users & 10 \\
\hline 3 & Modulation & $64 \mathrm{QAM}$ & 6 \\
\hline 4 & Channel Bandwidth & $20 \mathrm{MHz}$ \\
\hline 5 & Number of Spatial Streams & 1 \\
\hline
\end{tabular}

It is assumed that, WLAN network 1 is situated at longer distance i.e. in between $800 \mathrm{~m}-1.6 \mathrm{~km}$, WLAN Network 2 and 4 are situated above $400 \mathrm{~m}$ and below $800 \mathrm{~m}$ and WLAN Network 3 and 5 are situated below 400m distance. Hence after sensing their distance and QoS requirement WiMAX Base Station decides to allot highest QoS Resources for WLAN Network 2 and 4 with 64QAM , for WLAN 1 and 3 Base Station provides burst profile with 16 QAM and for WLAN Network 1 Base Station uses Burst Profile with QPSK.

\subsection{Results : Individual capacity of the network}

Table 10: Capacity of the network

\begin{tabular}{|c|c|c|}
\hline Network & Modulation & Capacity(bits/Sec/Hz) \\
\hline WiFi1 & QPSK & 3.5149 \\
\hline WiFi2 & 16QAM & 5.5997 \\
\hline WiFi3 & 64QAM & 6.7133 \\
\hline WiFi4 & 16QAM & 5.8042 \\
\hline WiFi5 & 64QAM & 7.8808 \\
\hline
\end{tabular}

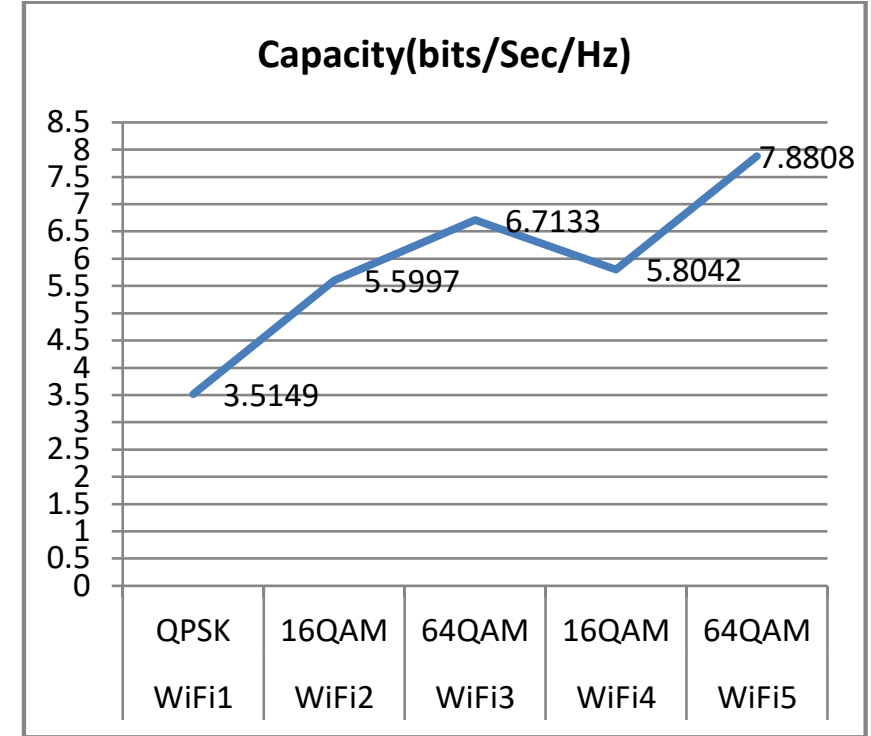

Fig. 11: Individual WLAN network capacity

Fig. 11 shows Individual WLAN capacity, it is quite obvious that for 64QAM, capacity or bit rate is more as compared to 16QAM and QPSK modulation schemes. Hence WLAN nearer to Base Station receives more data rates and WLAN at distant places receives data at lower rates. Also to combat BER Base station use robust modulation schemes for Remote WLAN so that data reliably travel through channel.

\subsection{Individual Channel Capacity for WLAN}

\begin{tabular}{|c|c|c|c|}
\hline & & \multicolumn{2}{|c|}{ Capacity(bits/Sec/Hz) } \\
\hline Network & Modulation & $\begin{array}{c}\text { Proportional } \\
\text { Resource }\end{array}$ & $\begin{array}{c}\text { Active Set } \\
\text { Optimization }\end{array}$ \\
\hline WiFi1 & QPSK & 3.5149 & 3.6003 \\
\hline WiFi2 & 16QAM & 5.5997 & 10.7364 \\
\hline WiFi3 & 64QAM & 6.7133 & 26.0336 \\
\hline WiFi4 & 16QAM & 5.8042 & 11.5842 \\
\hline WiFi5 & 64QAM & 7.8808 & 27.1639 \\
\hline
\end{tabular}

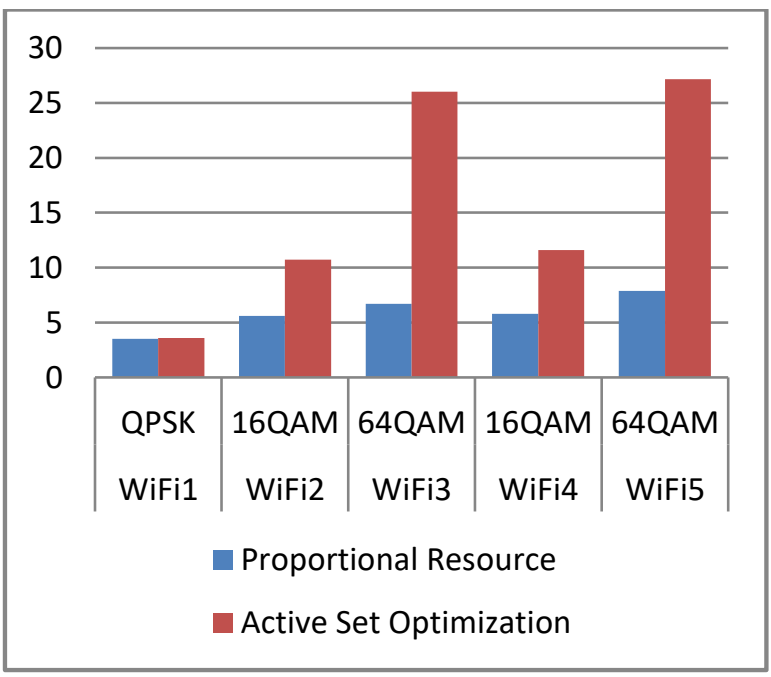

Fig. 12: Individual Network Capacity for PR and AS Algorithms

Fig. 12 Shows bar chart for Channel Capacity for Individual WLAN as it is seen, capacity achieved for each WLAN is more in case of Active Set Optimization. This is only because of 
more power allocation for higher priority allocation for WLAN 3 and WLAN 5. Moderate power is been allotted to WiFi2 and WiFi4 hence capacity achieved for them is less than WiFi3 and WiFi5 but more than WiFi1.

\subsection{Overall channel capacity}

Simulation is performed using the same parameters used as for Proportional Resource and Active Set algorithm. Experiment is conducted only for 50 users under 5 WLAN. From the results it is been observed that capacity is maximum for WiMAX system using Active Set Optimization. Capacity is increases as number of WLAN increases on the network this is because of Multiuser Diversity Gain.

\begin{tabular}{|c|c|c|c|}
\multicolumn{2}{c}{ Table 12: Overall capacity } \\
\hline & & \multicolumn{2}{c|}{ Capacity(bits/Sec/Hz) } \\
\hline Network & Modulation & $\begin{array}{c}\text { Proportional } \\
\text { Resource }\end{array}$ & $\begin{array}{c}\text { Active Set } \\
\text { Optimization }\end{array}$ \\
\hline WiFi1 & QPSK & 3.5149 & 3.6003 \\
\hline WiFi2 & 16QAM & 4.5573 & 7.16835 \\
\hline WiFi3 & 64QAM & 5.2759 & 13.45676667 \\
\hline WiFi4 & 16QAM & 5.408025 & 12.988625 \\
\hline WiFi5 & 64QAM & 5.90258 & 15.82368 \\
\hline
\end{tabular}

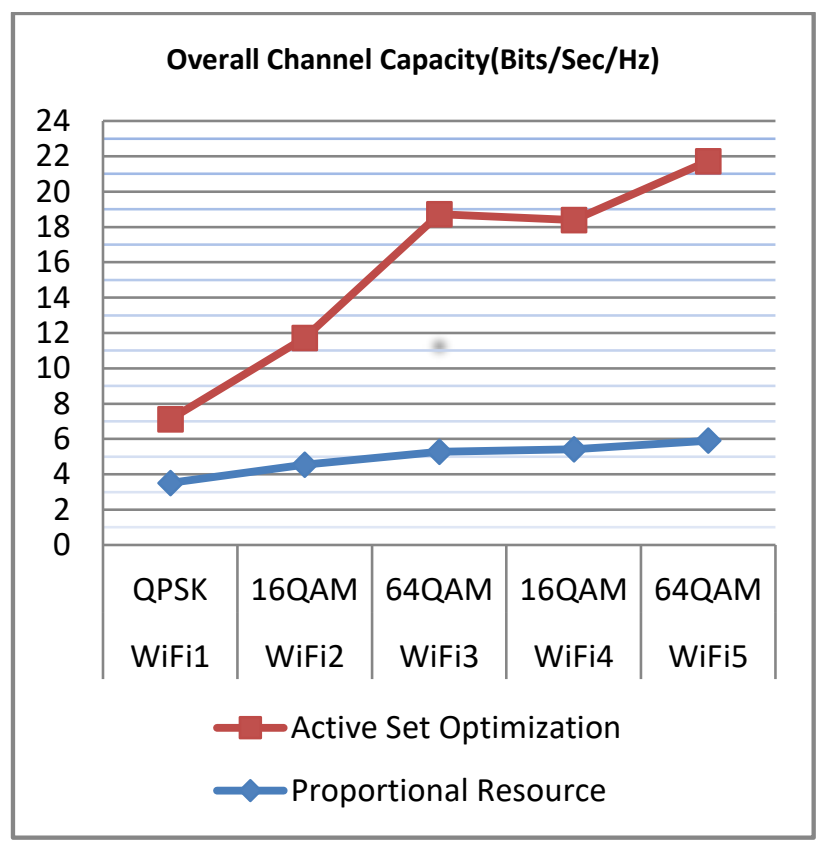

Fig.13: Overall channel capacity achieved using PR \& AS Algorithms

\subsection{Bit error rate for various WLAN only for} proportional resource

Fig.14 shows BER for various WLAN for proportional resource scheme.

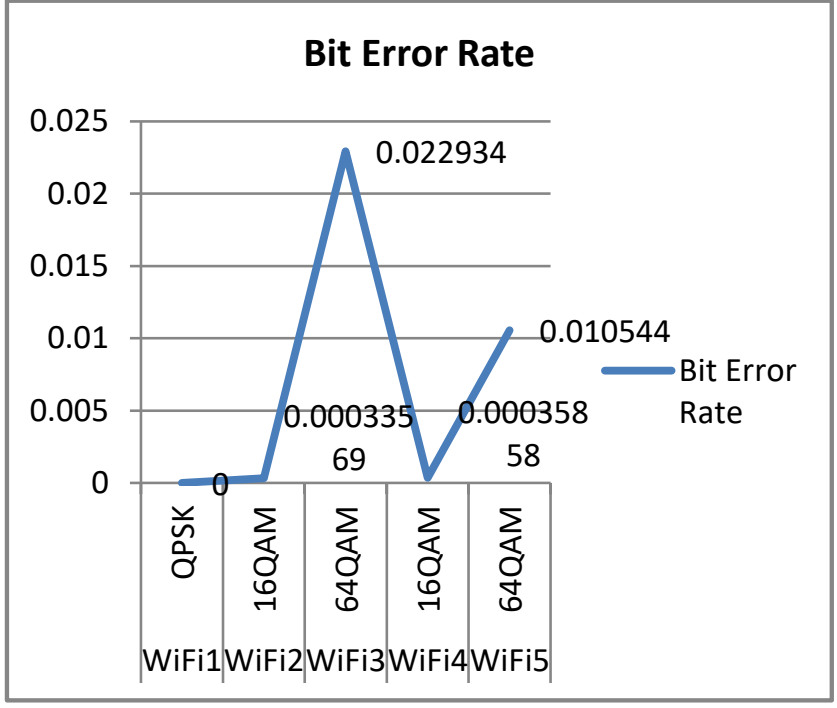

Fig. 14: BER for individual WLAN networks

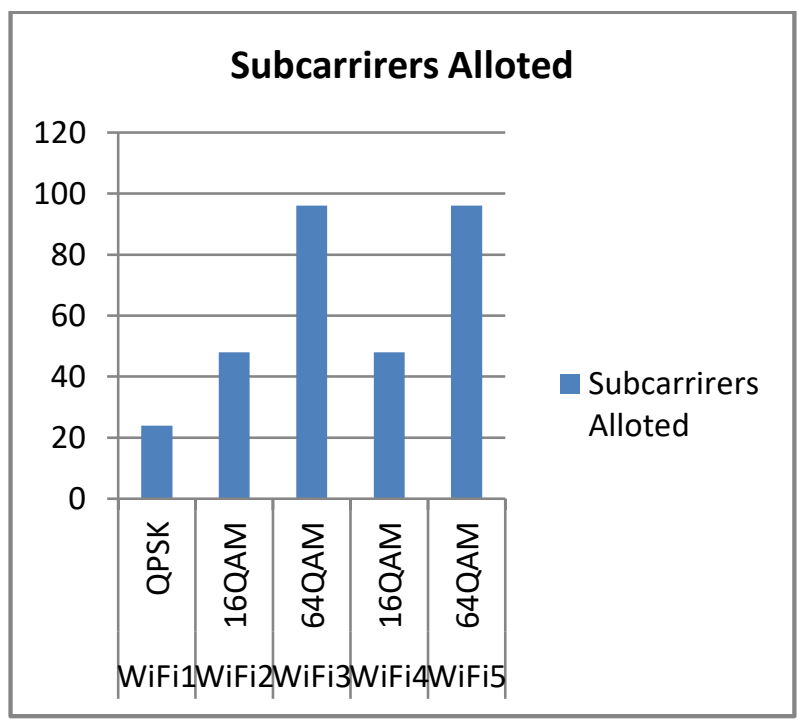

Fig. 15: Subcarrier allocation scheme adopted by WiMAX base station

\subsection{Number of errors in received symbols}

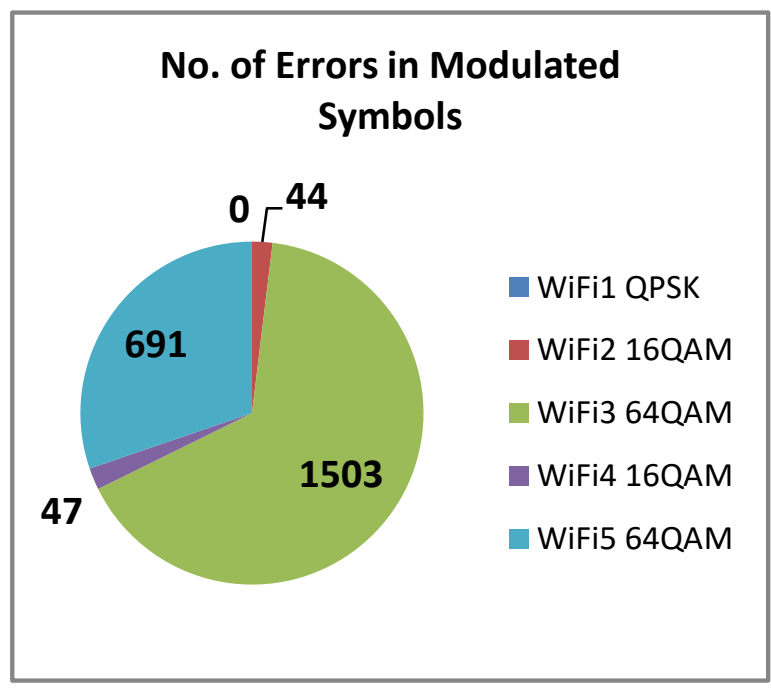

Fig. 16: Number of errors in received modulated words for various WLAN 


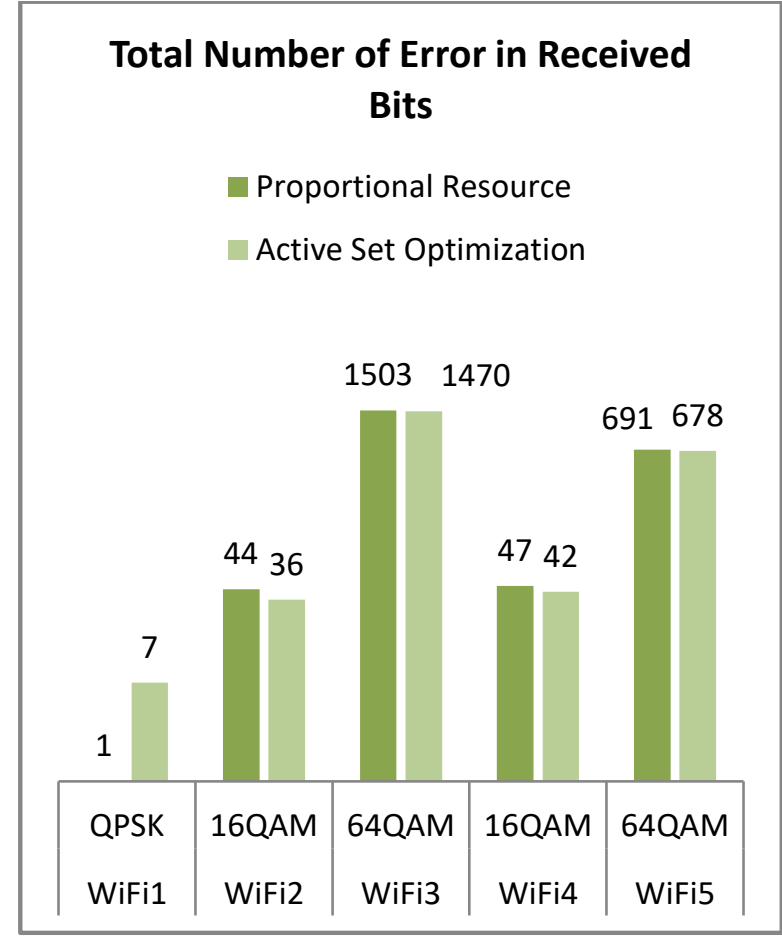

Fig.17: Number of errors in received symbols using PR and AS algorithms

\section{Conclusion}

The problem of multiuser downlink resource allocation in Mobile WiMAX system was studied. Simulation results show that information fed back and association among subcarriers play vital role to improve system performance. As compared to reduced complexity resource allocation Active Set Optimization and Genetic Algorithm seems especially attractive as the number of users increases for Image Data. It is observed through simulation that the System using Genetic Algorithm performs better than Active Set, Linear Resource Allocation in terms of significantly decreasing the computational complexity and achieve higher capacities, while being applicable to a more general class of systems. As Genetic Algorithm follows constraints of Stochastic processes it didn't give results highest in all Experiment Conducted. It is also observed that for Integer-Binary Objective function Performance of Genetic Algorithm is not that much satisfied because of its stochastic processing. Also processing time required to reach final optimize variables values is too much.

As in WiMAX latency period is too important because Base Station have to allot the resources in short span of time to its active users, GA fails to reach Optimize variables value within that period and took too much time. It is also observed that as number of subcarriers increases beyond 72 Genetic Algorithm couldn't find unknown variables values. So we come to the conclusion that for such type of Networks Active-Set Optimization is best suited instead of Genetic Algorithm though the fitness functions value is greater than the results obtained by Active-Set Optimization Technique.

\section{References}

[1] Stephen Boyd, Lieven Vandenberghe, "Convex Optimization", Cambridge University Press.

[2] Thomas Weise, "Global Optimization Algorithms- Theory and Application-", Version 2009-06-26.

[3] P. Rama Murthy, "Operations Research", New Age International Publishers.

[4] Banzhaf, Wolfgang, Nordin, Peter, Keller, Robert E., and Francone, Frank D.,"Genetic Programming - An
Introduction.", San Francisco, CA: Morgan Kaufmann Publishers and Heidelberg, Germany, 1998.

[5] S.Cheng, P. Lin, D. Huang and S. Yang, "A Study on Distributed/Centralized Scheduling for Wireless Mesh Network", International conference on Communications And Mobile Computing, pp. 599-604, 2006.

[6] J.Tao,F.Liu,Z.Zeng and A. Lin , "Throughput Enhancement in WiMAX Mesh Networks Using Concurrent Using Concurrent Transmission", International Conference on Wireless Communications, Networking and Mobile Computing 2005, Proceedings 2005 Vol. 2 , 2005.

[7] B. Makarevitch, "Distributed Scheduling for WiMAX Mesh Networks", Personal, Indoor and Mobile Radio Communications, 2006 IEEE 17th International Symposium, pp. 1-5, 2006.

[8] Abdel Karim Al Tamimi, Chakchai So-In and Raj Jain, "Modeling and Resource Allocation for Mobile Video over WiMAX Broadband Wireless Networks", IEEE Journal On Selected Areas In Communications, Vol. 28, No.3, April 2010.

[9] Shaik Yasmin Fathima, Md. Zia Ur Rahman, K. Murali Krishna, Shakira Bhanu,Mirza Shafi, "Side Lobe Suppression in NC-OFDM Systems Using Variable Cancellation Basis Function", IEEE Access, vol.5, no.1, pp. 9415-9421, 2017.

[10] M.L.M. Lakshmi, K.Rajkamal, S.V.A.V.Prasad, Md.Zia Ur Rahman, "Amplitude Only Linear Array Synthesis With Desired Nulls Using Evolutionary Computing Technique", The Applied of Computational Electromagnetics Society Journal, vol.31, no.11, pp. 1357-1361, November, 2016.

[11] Y. Murali Krishna, Md. Zia Ur Rahman and Dr B.V. Rama Mohana Rao, "Beam Steering in Smart Antennas using an Efficient Adaptive Signal Processing Algorithm," International Journal of Research and Reviews in Signal Acquisition and Processing, Vol. 1(3), Sep. 2011.

[12] Md. Zia Ur Rahmna, K. Murali Krishna, "Efficient Adaptive Beamforming Algorithms for Smart Antennas", International Journal of Control Theory and Applications, Vol.10, no.35, 2017, pp.173-181.

[13] Md. Zia Ur Rahman, et al., "A Low Complex adaptive algorithm for Antenna beam steering", IEEE 2011 International Conference on Signal Processing, Communications, Computing and Networking Technology (ICSCCN 2011), ISBN: 978-1-61284-653-8, pp.317-321, 2011. 